\title{
Impact of Pre-visit Contextual Data Collection on Patient-Physician Communication and Patient Activation: a Randomized Trial
}

\author{
Jeana M. Holt, Ph.D., DNP, RN, FNP-BC ' (D), Rachel Cusatis, Ph.D., MA ${ }^{2}$, \\ Aaron Winn, Ph.D ${ }^{3}$, Onur Asan, Ph.D. ${ }^{4}$, Charles Spanbauer, MS², \\ Joni S. Williams, MD, MPH' , Kathryn E. Flynn, Ph. D², Melek Somai, MD, MPH', \\ AkkeNeel Talsma, Ph.D., RN, FAAN ${ }^{7}$, Purushottam Laud, Ph. D2, \\ Gregory Makoul, Ph.D., MS , and Bradley H. Crotty, MD, MPH²
}

'University of Wisconsin-Milwaukee, College of Nursing, Milwaukee, WI, USA; ${ }^{2}$ Department of Medicine, Medical College of Wisconsin, Milwaukee, WI, USA; ${ }^{3}$ School of Pharmacy, Medical College of Wisconsin, Milwaukee, WI, USA; ${ }^{4}$ Stevens Institute of Technology, School of Systems \& Enterprises, Hoboken, NJ, USA; ${ }^{5}$ PatientWisdom, Inc. and Yale School of Medicine, New Haven, CT, USA.

BACKGROUND: Patient contextual data (PCD) are often missing from electronic health records, limiting the opportunity to incorporate preferences and life circumstances into care. Engaging patients through tools that collect and summarize such data may improve communication and patient activation. However, differential tool adoption by race might widen health care disparities.

OBJECTIVE: Determine if a digital tool designed to collect and present PCD improves communication and patient activation; secondarily, evaluate if use impacts outcomes by race.

DESIGN, SETTING, AND PARTICIPANTS: A pragmatic, two-armed, non-blinded, randomized controlled trial conducted during 2019 in a primary care setting.

INTERVENTION: The PCD tool (PatientWisdom) invited patients to identify preferences, values, goals, and barriers to care. Patients were randomized to a standard pre-visit email or facilitated enrollment with dedicated outreach to encourage use of the tool.

MAIN OUTCOMES AND MEASURES: Outcomes of interest were post-visit patient communication and patient activation measured by the Communication Assessment Tool (CAT) and Patient Activation Measure (PAM), respectively. Outcomes were evaluated using treatment-on-thetreated (TOT) and intention-to-treat (ITT) principles.

KEY RESULTS: A total of 301 patients were enrolled. Facilitated enrollment resulted in a five-fold increase in uptake of the PCD tool. TOT analysis indicated that the PCD tool was associated with notable increases in specific CAT items rated as excellent: "treated me with respect" (+ 13 percentage points; $p=0.04$ ), "showed interest in my ideas" (+ 14 percentage points; $p=0.03)$, "showed care and concern" (+ 16 percentage points; $p=0.02)$, and "spent about the right amount of time with me" (+ 11 percentage points; $p=0.05)$. There were no significant pre/post-visit differences in PAM scores between arms (4.41 percentage points; $p=0.58$ ). ITT results were similar.

Received August 29, 2020

Accepted December 29, 2020

Published online February 9, 2021
We saw no evidence of the treatment effect varying by race in ITT or TOT analyses.

CONCLUSIONS AND RELEVANCE: The inclusion of PCD enhanced essential aspects of patient-provider communication but did not affect patient activation. Outcomes did not differ by race.

TRIAL REGISTRATION: Clincaltrials.gov identifier: NCT03766841

KEY WORDS: patient contextual data; health information technology; patient-provider communication; patient participation; primary health care; randomized controlled trial; health care disparities.

J Gen Intern Med 36(11):3321-9

DOI: $10.1007 / \mathrm{s} 11606-020-06583-7$

(c) Society of General Internal Medicine 2021

$\mathrm{C}$ linicians have limited time to efficiently and systematically gather data about factors in patients' lives that affect health and care. Contextual data is highly relevant, a point reinforced by the estimate that clinical care accounts for only $20 \%$ of a patient's health status. ${ }^{1}$ Without this data, providers have an incomplete understanding of their patients, which may adversely affect patient-provider communication ${ }^{2}$ and patient activation, ${ }^{3}$ leading to less patient-centered care and suboptimal health outcomes. ${ }^{4-8}$ Patient contextual data (PCD) encompasses an individual's health values, goals, and preferences as well as personal and social determinants of health. ${ }^{9,10}$ While EHRs may improve aspects of patient-centered care, they were not designed to capture PCD and make it available at the point-of-care. $^{11}$

To improve the scalability, efficiency, and reliability of incorporating PCD into everyday practice, computers could facilitate the collection and distillation of contextual data. ${ }^{12-17}$ Ideally, such tools would sit atop the EHR and help humanize the electronic record by going beyond clinical data to provide 
a basis for effective health communication at the point-ofcare. ${ }^{9,13,18,19}$ Qualitative studies with one PCD tool indicated that pre-visit collection of PCD improved patient-provider communication and promoted a shift toward shared responsibility for information gathering and co-development of the care plan. ${ }^{9,10}$ Patient-users reported that reflecting on their health goals spurred them to action. ${ }^{9}$ Providers reported that incorporating PCD into the visit supported an unparalleled level of patient activation. ${ }^{10}$ These findings supported a deeper investigation of the PCD tool as a mechanism to improve individualized care. $^{13,14}$

Given the focus on helping patients share information about their lives, what matters to them, and to organize their thoughts ahead of clinical encounters, we hypothesized that the PCD tool would be associated with more effective communication ${ }^{9,10}$ and increased patient activation. ${ }^{20}$ Moreover, we expect clinician visibility into PCD to facilitate more effective communication about what matters to patients, which may be most apparent to patients in the form of relationally oriented communication tasks such as showing respect, care, concern, and interest.

It is important to note that there is a risk of health informatics interventions producing an inequality into care. ${ }^{21}$ In fact, ethnically and racially diverse and socioeconomically disadvantaged patients who stand to benefit most from the incorporation of PCD into care plans may be the least likely to adopt such tools. Nationally, $92 \%$ of White and $85 \%$ of Black Americans are online. ${ }^{22}$ However, there are varied profiles of Internet and technology use and non-use, ${ }^{23-25}$ which indicate that areas of the digital divide (e.g., sociodemographics) continue to evolve. Prior studies consistently show that Black patients are approximately 50\% less likely to engage in EHR portals, even after adjustment for socioeconomic status. ${ }^{26-29}$

Accordingly, the purpose of this study was to:

- evaluate the extent to which a PCD tool affects patientprovider communication and patient activation at the point-of-care; and

- assess potential differences in outcomes across populations whether differences or disparities in outcomes by race would be ameliorated or exacerbated. ${ }^{30}$

\section{METHODS}

\section{Design}

This study was a pragmatic two-armed, non-blinded, randomized clinical trial. A detailed study protocol is available. ${ }^{31}$ Research was conducted in the two largest primary care clinics at the Froedtert \& Medical College of Wisconsin Health Network, Milwaukee, WI, between May and October 2019. Patients were screened for inclusion based on demographic data (i.e., age, race/ethnicity) within the EHR. All patients with upcoming primary care appointments meeting eligibility criteria were sent an email (if email available) or a post-card invitation (if email unavailable). Patients who verbally consented to participate were stratified by race and then randomized in a 1:1 fashion to the control arm (single pre-visit email invitation to create an account in the PCD tool sent with the electronic appointment reminder) or the facilitated enrollment arm (research coordinator proactively supported enrollment and offered assistance, if necessary, to create a PCD tool account). All participants completed a pre-visit survey before their primary care appointment (both arms) and using the PCD tool (facilitated enrollment arm only). Following the visit, all participants were asked to complete a post-visit survey within 1 month (Fig. 1). The institutional review board at the Medical College of Wisconsin approved the study.

\section{Intervention}

Patient Contextual Data Tool. The EHR-integrated and HIPAA-compliant PCD tool (PatientWisdom, PatientWisdom, Inc., Madison, CT) is a mobile-responsive digital site that patients can access through the web to securely share PCD; it incorporates single sign-on integration with the EHR (Epic Systems, Verona, WI). PatientWisdom collects PCD directly from patients and summarizes information about health values, needs, goals, barriers, supports, risks, and preferences, as well as social and personal determinants of health. Content is collected in both free-text and choice (i.e., checkbox, radio button, matrix) formats. Development of the tool followed human-centered design and health literacy principles to improve communication and surface essential PCD elements. ${ }^{9,32-34}$

\section{Outcome Variables of Interest}

Patient-Provider Communication. Patients' perceptions of their primary care provider's interpersonal and communication skills were measured using the Communication Assessment Tool (CAT). ${ }^{35}$ The CAT was written at the fourth-grade reading level and employs a 5-point response scale (poor to excellent). It was validated in a sample with varied sociodemographic characteristics and yielded a high internal consistency (Cronbach's alpha $=0.96$ ). Scores are reported as percent "excellent." ${ }^{, 35}$ Responses to items were assessed individually and collated to calculate the overall proportion of "excellent" responses.

Patient Activation. Patient activation was assessed through the 13-item Patient Activation Measure (PAM), which has been validated in diverse and nationally representative samples. $^{20,36,37}$ Patient activation is the level of knowledge, skills, ability, and confidence an individual has to self-manage their day-to-day health. ${ }^{20}$ The instrument provides two metrics for examination, a score, and a level. The activation score is based on a 0 - to 100-point scale, and people can be categorized into four levels of activation (level $1=$ least activated to level $4=$ most activated). ${ }^{36}$ We examined the change in PAM scores from baseline to follow-up and between groups. 


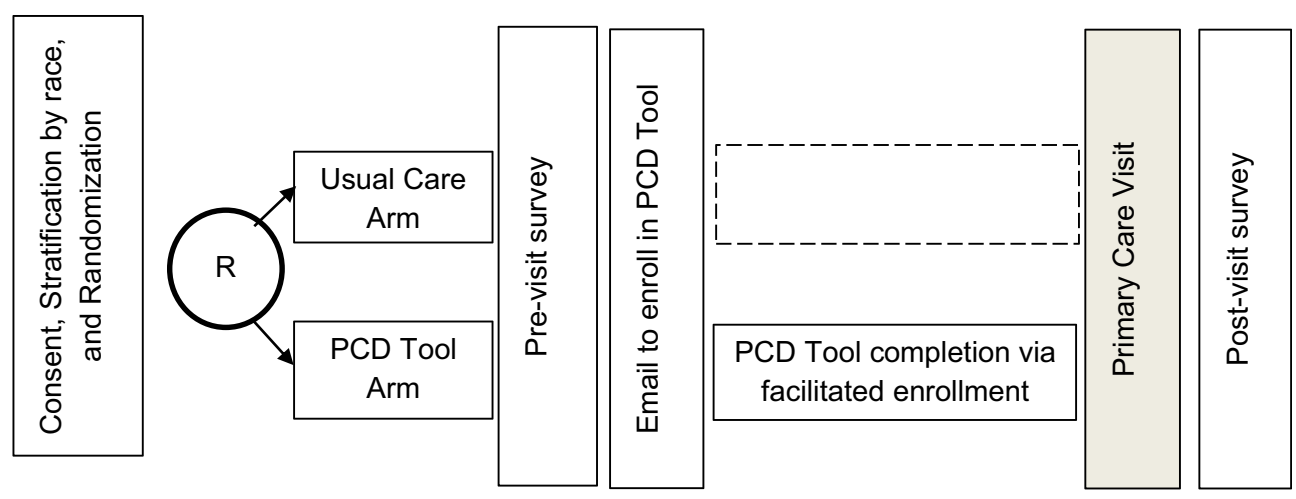

Figure 1 Randomized control trial study design. R, randomization; PCD, patient contextual data.

Sample Size and Power. The calculation of the study sample size was based on detecting differences in CAT scores between arms. We calculated a sample size of 250 for $88 \%$ power for a standardized effect size of 0.4 . Recruitment of 300 participants allowed for a $20 \%$ dropout rate.

\section{Data Collection and Enrollment Protocol}

Participants. Eligible participants were adults 18 years or older who self-identified as non-Hispanic White or nonHispanic Black, spoke and understood English, and were willing and able to give informed consent. Recruitment focused on patients who had an upcoming visit 1 to 4 weeks away at one of the participating clinics with an established provider $(\geq 1$ previous appointment with the provider within the last 12 months).

Enrollment. Individuals who met the inclusion criteria and consented to participate were enrolled and randomized. Participants were stratified equally by race to the control or facilitated enrollment arms.

Pre-visit and Post-visit Surveys. Participants completed the pre-visit survey via REDCap ${ }^{38}$ using an emailed link, over the telephone, or in-person with one of the research staff after verbal consent. The pre-visit survey measured patient activation (PAM), ${ }^{36}$ technology use and acceptance (HINTS-5, Cycle-1), ${ }^{39}$ patient-provider communication from previous primary care visit(s) (CG-CAHPS-3.0), ${ }^{40}$ global health (PROMIS Global Health-v1.2) ${ }^{41}$ health literacy, ${ }^{42}$ and sociodemographic characteristics. After completing the pre-visit survey, participants who attended their scheduled primary care visit received an email invitation to complete the post-visit survey. The post-visit survey included the $\mathrm{PAM}^{36}$ and CAT. ${ }^{35}$

Analysis. We used chi-square tests for categorical variables and independent-sample $t$ tests for continuous variables to examine baseline differences between study arms. For the primary outcome (CAT), we used linear regression to determine the effect of the intervention on post-visit communication, adjusting for pre-visit CG-CAHPS scores to account for any differences between physicians. For the secondary outcome (PAM), we used a $t$ test to determine the effect of the intervention on change in patient activation of race by interacting race with study arm for both outcomes.

The initial analysis used an intention-to-treat (ITT) approach, comparing patients by their study arm. Because the trial was designed to assess the impact of tool usage, rather than the impact of facilitated enrollment per se, we also completed a second treatment-on-the-treated (TOT) analysis using an instrumental variable approach. ${ }^{43,44}$ In the TOT analysis, participants' data are grouped whether they used PCD tool (created an account and added data) or not. The TOT allows us to estimate the effect of using the PCD tool instead of being assigned to facilitated enrollment and corrects for cross-over that may occur in the pragmatic trial. For TOT analysis, we used a two-stage least squares regression. ${ }^{45,46}$ The first stage of the model estimated if a person used the PCD tool in the follow-up period as a function of assigned treatment arm and their corresponding covariates. The second stage identified the causal impact of using the PCD tool using the ivregress command in Stata. We report TOT results in the text and show both in the tables.

We used multiple imputation using chained equations ${ }^{47}$ (i.e., Markov chain Monte Carlo) stratified by the treatment arm to address missing data. The imputation algorithm included all baseline individual PAM $^{36}$ and CG-CAHPS ${ }^{40}$ elements, patients' responses on whether the provider discussed contextual data, health literacy ${ }^{42}$, PROMIS ${ }^{41}$ scores, and demographics. For all results, a $p$ value of $\leq 0.05$ was considered statistically significant.

\section{RESULTS}

\section{Study Participants}

Figure 2 displays the CONSORT Participant Flow ${ }^{48}$ diagram. A total of 3237 patients were invited to participate. Of those, 2735 (84\%) did not respond to the invitation to enroll, and $201(6 \%)$ 
declined to participate. In total, $301(9 \%)$ participants were enrolled and randomized, and $185(6 \%)$ were included in the analysis.

There were no demographic differences between the arms. Sixty-four percent of the participants were female, $67 \%$ White, $48 \%$ over 65 years, and $42 \%$ retired. Twenty percent of participants reported a household income of less than $\$ 10,000$ annually, and $43 \%$ of participants reported at least some difficulty with meeting monthly bill payments (Table 1).

\section{PCD Tool Adoption}

Facilitated enrollment resulted in a five-fold increase in uptake of the PCD tool (30\% vs. $6 \%$ for the control group). The most prevalent form of facilitation was telephone follow-up to remind patients about the PCD tool.

\section{Communication}

As there was cross-over between arms due to the pragmatic nature of the study, we focused on the TOT results to assess

\section{CONSORT Flowchart of Participants}

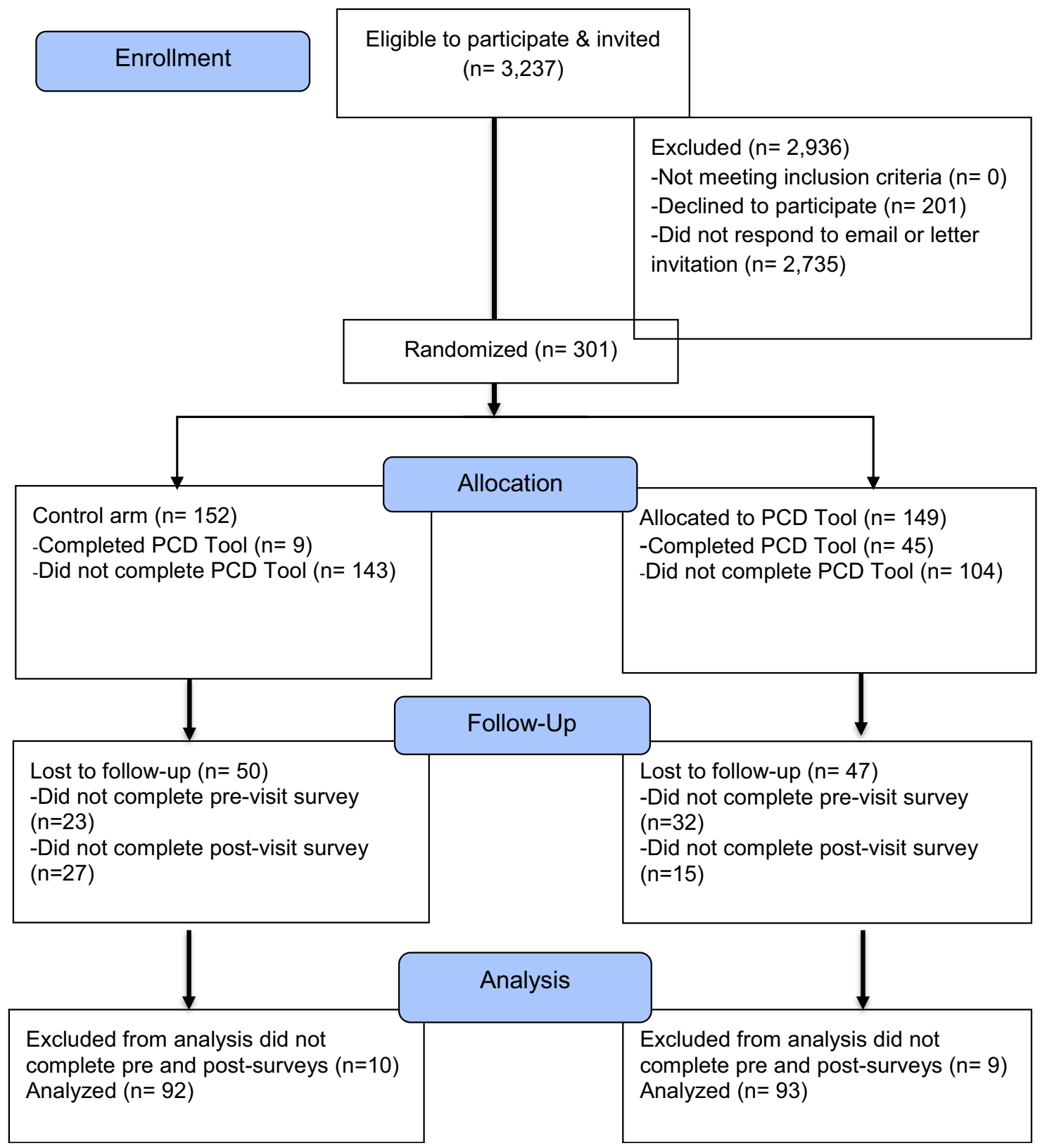

Figure 2 CONSORT flowchart of participants. 
Table 1 Baseline Patient Characteristics

\begin{tabular}{|c|c|c|c|c|}
\hline & \multicolumn{3}{|l|}{ Percentages } & \multirow[t]{2}{*}{$p$ value } \\
\hline & Total $(N=185)$ & Control $(n=92)$ & PCD tool $(n=93)$ & \\
\hline \multicolumn{4}{|l|}{ Sex } & \multirow[t]{7}{*}{0.91} \\
\hline Female & 64.13 & 63.74 & 64.52 & \\
\hline \multicolumn{4}{|l|}{ Age (in years) } & \\
\hline 50 or less & 21.08 & 19.57 & 22.58 & \\
\hline $51-65$ & 29.73 & 23.91 & 35.48 & \\
\hline $66-75$ & 32.43 & 34.78 & 30.11 & \\
\hline 75 or more & 16.76 & 21.74 & 11.83 & \\
\hline Race & & & & \multirow{3}{*}{0.60} \\
\hline Black/African American & 32.97 & 34.78 & 31.18 & \\
\hline White & 67.03 & 65.22 & 68.82 & \\
\hline \multicolumn{4}{|l|}{ Education } & \multirow[t]{6}{*}{0.88} \\
\hline Some high school & 4.32 & 4.35 & 4.3 & \\
\hline High school or GED & 18.38 & 20.65 & 16.13 & \\
\hline Some college or 2-year degree & 28.11 & 25 & 31.18 & \\
\hline 4-year college grad & 18.38 & 18.48 & 18.28 & \\
\hline More than 4 years of college & 30.81 & 31.52 & 30.11 & \\
\hline \multicolumn{4}{|l|}{ Marital status } & \multirow[t]{6}{*}{0.18} \\
\hline Single, never married & 34.05 & 34.78 & 33.33 & \\
\hline Married or domestic partnership & 43.24 & 36.96 & 49.46 & \\
\hline Widowed & 9.73 & 10.87 & 8.6 & \\
\hline Divorced & 11.35 & 14.13 & 8.6 & \\
\hline Separated & 1.62 & 3.26 & 0 & \\
\hline \multicolumn{4}{|l|}{ Employment status } & \multirow{9}{*}{0.53} \\
\hline Employed for wages & 31.89 & 28.26 & 35.48 & \\
\hline Self employed & 3.78 & 5.43 & 2.15 & \\
\hline Out of work and looking & 1.62 & 1.09 & 2.15 & \\
\hline Out of work but not currently looking & 2.7 & 3.26 & 2.15 & \\
\hline A homemaker & 1.62 & 0 & 3.23 & \\
\hline A student & 1.08 & 1.09 & 1.08 & \\
\hline Retired & 42.16 & 45.65 & 38.71 & \\
\hline Unable to work & 15.14 & 15.22 & 15.05 & \\
\hline Household income & & & & 0.71 \\
\hline Less than $\$ 10,000$ & 20.11 & 24.18 & 15.91 & \\
\hline$\$ 10,000$ to less than & 10.61 & 12.09 & 9.09 & \\
\hline$\$ 20,000$ to less than & 8.94 & 5.49 & 12.5 & \\
\hline$\$ 30,000$ to less than & 4.47 & 4.4 & 4.55 & \\
\hline$\$ 40,000$ to less than & 7.82 & 6.59 & 9.09 & \\
\hline$\$ 50,000$ to less than & 12.29 & 13.19 & 11.36 & \\
\hline$\$ 75,000$ to less than & 11.73 & 12.09 & 11.36 & \\
\hline$\$ 100,000$ to less than & 11.73 & 9.89 & 13.64 & \\
\hline$\$ 150,000$ or more & 12.29 & 12.09 & 12.5 & \\
\hline Insurance details* & & & & \\
\hline Directly purchased commercial & 26.89 & 27.12 & 26.67 & 0.96 \\
\hline Employer-sponsored insurance & 50.75 & 45.16 & 55.56 & 0.230 \\
\hline Medicaid, med assistance or any kind of governmental assistance & 33.09 & 32.88 & 33.33 & 0.95 \\
\hline Any difficulty to meet monthly payments & & & & 0.67 \\
\hline Extremely difficult & 6.01 & 5.43 & 6.59 & \\
\hline Very difficult & 9.29 & 11.96 & 6.59 & \\
\hline Somewhat difficult & 13.66 & 11.96 & 15.38 & \\
\hline Slightly difficult & 13.66 & 11.96 & 15.38 & \\
\hline Not difficult at all & 57.38 & 58.7 & 56.04 & \\
\hline Confident filling out forms by yourself & & & & 0.54 \\
\hline Extremely & 65.76 & 67.03 & 64.52 & \\
\hline Quite a bit & 23.37 & 21.98 & 24.73 & \\
\hline Somewhat & 7.07 & 5.49 & 8.6 & \\
\hline A little bit & 2.72 & 3.3 & 2.15 & \\
\hline Not at all & 1.09 & 2.2 & 0 & \\
\hline Baseline overall CG-CAHPS** & 0.689 & 0.759 & 0.687 & 0.88 \\
\hline PROMIS v1.2 & & & & \\
\hline Physical health, mean (SD) & $44.66(10.18)$ & $43.90(9.79)$ & $45.40(10.56)$ & 0.32 \\
\hline Mental health, mean (SD) & $47.02(9.63)$ & $46.83(9.90)$ & $47.22(9.35)$ & 0.78 \\
\hline Baseline PAM score, mean (SD) & $61.5(1.2)$ & $59.3(1.8)$ & $63.7(1.5)$ & 0.58 \\
\hline Baseline PAM level & & & & 0.23 \\
\hline Level 1 (lowest) & 12.97 & 16.3 & 9.68 & \\
\hline Level 2 & 23.24 & 27.17 & 19.35 & \\
\hline Level 3 & 41.08 & 36.96 & 45.16 & \\
\hline Level 4 (highest) & 22.7 & 19.57 & 25.81 & \\
\hline
\end{tabular}

CG-CAHPS ${ }^{40}$, Clinician and Group Consumer Assessment of Healthcare Providers and Systems; PROMIS ${ }^{60}$, Patient Reported Outcomes Measure Information System; PAM ${ }^{36}$, Patient Activation Measure

* Participants could choose more than one insurance category

**Overall CG-CAHPS was scored as the proportion of items with "excellent" as the response. Individual items are scored as "excellent" = 1 and all other responses $=0$ 
Table 2 Impact of Patient Contextual Data Tool on Patient-Provider Communication and Patient Activation

\begin{tabular}{|c|c|c|c|c|c|c|c|c|c|c|}
\hline & \multirow[b]{2}{*}{$\mathrm{UC}$} & \multirow[b]{2}{*}{$95 \% \mathrm{CI}$} & \multirow{3}{*}{$\begin{array}{l}\text { PCD } \\
\text { tool } \\
93.00\end{array}$} & \multirow[b]{2}{*}{$95 \% \mathrm{CI}$} & \multicolumn{3}{|c|}{ Intention-to-treat } & \multicolumn{3}{|c|}{ Treatment-on-the-treated } \\
\hline & & & & & Difference & $95 \% \mathrm{CI}$ & $\begin{array}{l}p \\
\text { value }\end{array}$ & Difference & $95 \% \mathrm{CI}$ & $\begin{array}{l}p \\
\text { value }\end{array}$ \\
\hline$N$ & 92.00 & & & & & & & & & \\
\hline Change in PAM score & 5.65 & $\begin{array}{l}(1.31 \\
9.98)\end{array}$ & 1.86 & $\begin{array}{l}(-1.16 \\
4.89)\end{array}$ & -1.23 & $(-5.78$ & 0.60 & -4.41 & $\begin{array}{l}(-19.90 \\
1108)\end{array}$ & 0.58 \\
\hline Overall CAT & 0.69 & $\begin{array}{l}(0.60 \\
0.77)\end{array}$ & 0.77 & $\begin{array}{l}(0.70 \\
0.84)\end{array}$ & 0.09 & $\begin{array}{l}(-0.01 \\
0.20)\end{array}$ & 0.08 & 0.40 & $\begin{array}{l}(-0.07 \\
0.86)\end{array}$ & 0.09 \\
\hline Individual items & & & & & & & & & & \\
\hline $\begin{array}{l}\text { Greeted me in a way that } \\
\text { made me feel comfortable }\end{array}$ & 0.70 & $\begin{array}{l}(0.61, \\
0.80)\end{array}$ & 0.81 & $\begin{array}{l}(0.73, \\
0.89)\end{array}$ & 0.11 & $\begin{array}{l}(-0.02 \\
0.23)\end{array}$ & 0.09 & 0.42 & $\begin{array}{l}(-0.11 \\
0.95)\end{array}$ & 0.12 \\
\hline Treated me with respect & 0.73 & $\begin{array}{l}(0.64 \\
0.82)\end{array}$ & 0.86 & $\begin{array}{l}(0.79 \\
0.93)\end{array}$ & 0.14 & $\begin{array}{l}(0.02 \\
0.25)\end{array}$ & 0.02 & 0.53 & $\begin{array}{l}(0.01 \\
1.04)\end{array}$ & 0.04 \\
\hline Showed interest in my ideas & 0.63 & $\begin{array}{l}(0.53 \\
0.73)\end{array}$ & 0.77 & $\begin{array}{l}(0.69 \\
0.86)\end{array}$ & 0.15 & $\begin{array}{l}(0.03 \\
0.28)\end{array}$ & 0.02 & 0.59 & $\begin{array}{l}(0.06, \\
1.13)\end{array}$ & 0.03 \\
\hline $\begin{array}{l}\text { Understood my main health } \\
\text { concerns }\end{array}$ & 0.69 & $\begin{array}{l}(0.59 \\
0.78)\end{array}$ & 0.74 & $\begin{array}{l}(0.65 \\
0.83)\end{array}$ & 0.07 & $\begin{array}{l}(-0.06 \\
0.19)\end{array}$ & 0.31 & 0.31 & $\begin{array}{l}(-0.21 \\
0.83)\end{array}$ & 0.24 \\
\hline Paid attention to me & 0.73 & $\begin{array}{l}(0.64 \\
0.82)\end{array}$ & 0.84 & $\begin{array}{l}(0.76 \\
0.92)\end{array}$ & 0.12 & $\begin{array}{l}(0.00 \\
0.23)\end{array}$ & 0.05 & 0.46 & $\begin{array}{l}(-0.06 \\
0.98)\end{array}$ & 0.08 \\
\hline $\begin{array}{l}\text { Let me talk without } \\
\text { interruptions }\end{array}$ & 0.73 & $\begin{array}{l}(0.67 \\
0.82)\end{array}$ & 0.77 & $\begin{array}{l}(0.69 \\
0.86)\end{array}$ & 0.06 & $\begin{array}{l}(-0.07 \\
0.18)\end{array}$ & 0.37 & 0.32 & $\begin{array}{l}(-0.19 \\
0.84)\end{array}$ & 0.22 \\
\hline $\begin{array}{l}\text { Gave me as much } \\
\text { information as I wanted }\end{array}$ & 0.63 & $\begin{array}{l}(0.53 \\
0.73)\end{array}$ & 0.72 & $\begin{array}{l}(0.63 \\
0.81)\end{array}$ & 0.10 & $\begin{array}{l}(-0.03 \\
0.23)\end{array}$ & 0.13 & 0.38 & $\begin{array}{l}(-0.14 \\
0.90)\end{array}$ & 0.15 \\
\hline $\begin{array}{l}\text { Talked in terms that I could } \\
\text { understand }\end{array}$ & 0.76 & $\begin{array}{l}(0.67 \\
0.85)\end{array}$ & 0.81 & $\begin{array}{l}(0.73 \\
0.89)\end{array}$ & 0.05 & $\begin{array}{l}(-0.07 \\
0.17)\end{array}$ & 0.39 & 0.25 & $\begin{array}{l}(-0.28 \\
0.76)\end{array}$ & 0.36 \\
\hline $\begin{array}{l}\text { Checked to be sure I } \\
\text { understood everything }\end{array}$ & 0.67 & $\begin{array}{l}(0.58 \\
0.77)\end{array}$ & 0.71 & $\begin{array}{l}(0.62 \\
0.80)\end{array}$ & 0.04 & $\begin{array}{l}(-0.09 \\
0.18)\end{array}$ & 0.52 & 0.23 & $\begin{array}{l}(-0.30 \\
0.76)\end{array}$ & 0.40 \\
\hline $\begin{array}{l}\text { Encouraged me to ask } \\
\text { questions }\end{array}$ & 0.64 & $\begin{array}{l}(0.54 \\
0.74)\end{array}$ & 0.70 & $\begin{array}{l}(0.60 \\
0.79)\end{array}$ & 0.07 & $\begin{array}{l}(-0.07 \\
0.20)\end{array}$ & 0.32 & 0.30 & $\begin{array}{l}(-0.22 \\
0.83)\end{array}$ & 0.25 \\
\hline $\begin{array}{l}\text { Involved me in decisions as } \\
\text { much as I wanted }\end{array}$ & 0.64 & $\begin{array}{l}(0.54 \\
0.74)\end{array}$ & 0.72 & $\begin{array}{l}(0.63 \\
0.81)\end{array}$ & 0.09 & $\begin{array}{l}(-0.05 \\
0.22)\end{array}$ & 0.19 & 0.41 & $\begin{array}{l}(-0.12 \\
0.93)\end{array}$ & 0.13 \\
\hline $\begin{array}{l}\text { Discussed next steps, } \\
\text { including any follow-up plans }\end{array}$ & 0.71 & $\begin{array}{l}(0.61, \\
0.80)\end{array}$ & 0.73 & $\begin{array}{l}(0.64, \\
0.82)\end{array}$ & 0.03 & $\begin{array}{l}(-0.09 \\
0.16)\end{array}$ & 0.60 & 0.21 & $\begin{array}{l}(-0.31 \\
0.73)\end{array}$ & 0.43 \\
\hline Showed care and concern & 0.66 & $\begin{array}{l}(0.57 \\
0.76)\end{array}$ & 0.82 & $\begin{array}{l}(0.74 \\
0.90)\end{array}$ & 0.16 & $\begin{array}{l}(0.04 \\
0.29)\end{array}$ & 0.01 & 0.63 & $\begin{array}{l}(0.10 \\
1.16)\end{array}$ & 0.02 \\
\hline $\begin{array}{l}\text { Spent the right amount of } \\
\text { time with me }\end{array}$ & 0.70 & $\begin{array}{l}(0.60 \\
0.79)\end{array}$ & 0.81 & $\begin{array}{l}(0.73 \\
0.89)\end{array}$ & 0.12 & $\begin{array}{l}(-0.00 \\
0.24)\end{array}$ & 0.05 & 0.53 & $\begin{array}{l}(0.00 \\
1.05)\end{array}$ & 0.05 \\
\hline
\end{tabular}

Intention-to-treat and treatment-on-the-treated $C A T^{28}$-related results are estimated using a linear regression model adjusting for baseline top-coded $C G-C A H P S^{34}$. Overall CAT was scored as the proportion of items with "excellent" as the response. Individual CAT items are scored as "excellent" = 1 and all other responses $=0$

UC, usual care (control arm); PCD, patient contextual data; CAT, Communication Assessment Tool; CG-CAHPS, Clinician and Group Consumer Assessment of Healthcare Providers and Systems; PAM ${ }^{30}$, Patient Activation Measure

the impact of the PCD tool. In the post hoc TOT analysis, the higher overall CAT score (i.e., summary score across all items) trended with PCD tool use but did not reach a statistical significance $(p=0.09)$. In post hoc item-level TOT analyses, there were marked increases in scores for specific CAT items: Use of the PCD tool was associated with gains in "treated me with respect" ( $86 \%$ vs. $73 \%, p=0.04)$, "showed interest in my ideas" (77\% vs. $63 \%, p=0.03)$, "showed care and concern" ( $82 \%$ vs. $66 \%, p=0.02$ ), and "spent about the right amount of time with me" ( $81 \%$ vs. $70 \%, p=0.05)$. Differences on all other items were in the same direction, but not statistically significant.

Results from multiple imputation (Appendix Table 4) using chained equations ${ }^{47}$ and ITT results are in Table 2 and parallel the TOT results. Results were also reweighted to statistically ensure equal representation of White and Black participants in the analysis (Appendix Table 5); these are aligned with the results presented in Table 2.

\section{Patient Activation}

The pre-visit survey overall mean PAM score was 61.5 (SD = 1.2), which aligns with a level 3 of activation, indicating that a person is taking action to maintain or improve their health
(Table 1). The overall mean compares well with a national sample in which the mean PAM score was 61.9. ${ }^{36}$ The control arm baseline PAM score was $59.3(\mathrm{SD}=1.8)$, and the facilitated enrollment arm was $63.7(\mathrm{SD}=1.5)$, a difference that approaches a statistical significance $(p=0.06)$. No differences were observed in PAM scores through the TOT analysis (Table 2).

\section{Assessment of Differences by Race}

When testing for an interaction between race and study arm, neither of the interaction terms was statistically significant $(\mathrm{CAT} p=0.80 ; \operatorname{PAM} p=0.31)$. These findings are presented in Table 3. When comparing Black $(M=55.3, \mathrm{SD}=1.7)$ versus White $(M=64.6, \mathrm{SD}=1.5)$ participants' baseline mean activation scores, Black participants had a significantly lower baseline score $(-9.32 ; 95 \% \mathrm{CI}=-14.08,-4.57 ; p<0.001)$. Black participants experienced an average 5.6-point $(\mathrm{SD}=-$ 3.5-point) increase in the PAM score in both arms, which was higher than White participants' average change in the PAM score in both arms $(M=3$-point; $\mathrm{SD}=2.15$-point $)$. The findings are suggestive but did not rise to the level of statistical significance and may be due to chance. 
Table 3 Interaction Between Race and Treatment Effect in the Intention-to-Treat Analysis

\begin{tabular}{lc}
\hline \hline & $\boldsymbol{p}$ value \\
\hline$N$ & 185 \\
Change in PAM score & 0.31 \\
Overall CAT & 0.80 \\
Individual items & 0.11 \\
Greeted me in a way that made me feel comfortable & 0.73 \\
Treated me with respect & 0.64 \\
Showed interested in my ideas & 0.23 \\
Understood my main health concerns & 0.26 \\
Paid attention to me & 0.90 \\
Let me talk without interruptions & 0.06 \\
Gave me as much information as I wanted & 0.23 \\
Talked in terms that I could understand & 0.53 \\
Checked to be sure I understood everything & 0.28 \\
Encouraged me to ask questions & 0.64 \\
Involved me in decisions as much as I wanted & 0.41 \\
Discussed next steps, including follow-up plans & 0.06 \\
Showed care and concern & 0.51 \\
Spent the right amount of time with me &
\end{tabular}

Intention-to-treat $P A M^{30}$-related results are estimated using a linear regression model adjusting for race, treatment, an interaction between race and treatment, and baseline PAM score. We report the $p$ value on the interaction term. Intention-to-treat $C A T^{28}$-related results are estimated using a linear regression model adjusting for race, treatment, an interaction between race and treatment, and baseline top-coded $C G$ CAHPS ${ }^{34}$. We report the $p$ value on the interaction term. Overall CAT was scored as the proportion of items with "excellent" as the response. Individual items are scored as "excellent" = 1 and all other responses $=0$

PAM, Patient Activation Measure; CAT, Communication Assessment Tool; CG-CAHPS, Clinician and Group Consumer Assessment of Healthcare Provides and Systems

\section{DISCUSSION}

This randomized trial assessed the extent to which a consumer informatics tool - designed to securely capture PCD and share a summary within the EHR - impacts patient-provider communication and patient activation. We found that people who used the PCD tool reported improvements in essential elements of patient-provider communication, but there was no impact on patient activation.

In our study, patients who completed the PCD tool were significantly more likely to report that their provider treated them with respect, valued their ideas, and showed care and concern. Moreover, despite the well-known time constraints imposed on primary care clinicians, ${ }^{49}$ patients who used the PCD tool rated physicians spending the right amount of time with them significantly higher than did non-PCD tool users. These results, in conjunction with previously published results from interviews with primary care clinicians who used the PCD tool for pre-visit planning and within-visit discussions ${ }^{10}$ as well as focus groups with PCD tool users, ${ }^{9}$ suggest that the PCD tool adds efficiency to the clinic visit without compromising the patient-provider relationship. In fact, the relationship is enhanced. Notably, we saw higher scores among users in the TOT analysis in certain CAT items, even in the context of high baseline communication scores. Our findings demonstrate the benefit of this PCD tool in facilitating effective communication skills and relationship dynamics, the core components of patient-centered care. ${ }^{50-52}$
While the PCD tool was associated with higher scores for every CAT item, the fact that some differences were large and statistically significant while others were relatively minor serves as a validity check in the context of everyday clinical practice. More specifically, one would expect patients using the PCD tool to feel that their clinician treated them with respect, showed care and concern, and showed interest in their ideas because the PCD tool focuses on what matters to them. Similarly, patients using the PCD tool might be more likely to report that their clinician spent the right amount of time with them because their needs are being met as a function of sharing priorities. In contrast, one would not expect much of a difference in patient perception of tasks that are distal to contents of the PCD tool; indeed, the smallest differences were observed for discussing next steps, checking to be sure the patient understood everything, talking in understandable terms, and letting the patient talk without interruptions.

In this study, we sought to understand if PCD tool usage would narrow differences in communication and patient activation by race or worsen them because the technology might not be accessible to some. We saw no evidence of the treatment effect, either in ITT or in TOT analyses, varying by race. Similar increases in the change in PAM scores for both races bolster the observation that including this PCD tool as part of the primary care visit did not introduce a disparity or barrier. Enriching the encounter with PCD collected directly from patients may be one potent way to improve health equity by addressing implicit bias and structural racism. ${ }^{53}$

These findings support the importance of carefully designed PCD tools and other interventions aimed at increasing the patient's ability to communicate effectively with their provider. In the COVID-era surge in telehealth care, ${ }^{54} \mathrm{PCD}$ tools that collect pre-visit data are even more critical. PCD tools can substitute for the work completed by medical assistants (e.g., agenda, chief complaint), to assist providers with where a patient wants to focus the visit. ${ }^{55}$ In pre-COVID studies, a patient-prioritization discussion ${ }^{56}$ aid enhanced decisionquality outcomes and patient-provider communication across diverse populations. ${ }^{46}$

\section{Limitations and Strengths}

The study has limitations. First, we cannot comment on how effective the intervention would be in other settings or populations. Milwaukee, WI, is a geographical area noted for its segregation and disparities among populations. ${ }^{57}$ The results require replication in other samples. Second, the PCD tool had been implemented previously, and therefore, patients could not be randomized to receiving an invitation or not. While we used several techniques to account for likelihood to self-select into using the tool, selection bias may persist. Third, we did not reach parity in retaining equal numbers of Black (33\%) and White $(67 \%)$ participants, which may have influenced the results. Additional strategies for recruiting and retaining Black participants such as community information sessions and 
network sampling ${ }^{58}$ may have improved the number of retained Black participants. Fourth, we obtained limited screening data about eligible patients. Therefore, we can only present a comparison of age of the population and sample ( $M=$ 68 vs. 60 years). Last, our results are based on the use of a particular PCD tool and may not generalize to other tools. Despite these limitations, the study has meaningful implications for the redesign of health information technology to meet the needs of both patients and clinicians.

\section{CONCLUSION}

Use of the consumer informatics tool to collect and summarize PCD was associated with improvements in essential aspects of patient-physician communication, but not in patient activation. We did not see outcome differences by race. Future research should investigate the influence of socioeconomic position, ${ }^{59}$ education, and health literacy, on baseline racial differences of patient activation. A follow-up study will assess organizational characteristics that affected patient and clinician use of the PCD tool.

Corresponding Author: Jeana M. Holt, Ph.D., DNP, RN, FNP-BC; University of Wisconsin-Milwaukee, College of Nursing, Milwaukee, WI, USA (e-mail: jmholt@uwm.edu).

Funding The project described was supported by the National Center for Advancing Translational Sciences, National Institutes of Health (NIH), Award Number (UL1TROO1436), Health Resources and Services Administration (HRSA) Award Number (T32HP10030), and the Advancing a Healthier Wisconsin Endowment Award Number (5520480).

\section{Compliance with Ethical Standards:}

Conflict of Interest: Bradley Crotty reports being an advisor for Buoy Health. Gregory Makoul reports employment with PatientWisdom, Inc. He did not participate in the analysis of trial data.

Disclaimer: The content is solely the responsibility of the authors and does not necessarily represent the official views of the NIH, HRSA, or the Advancing a Healthier Wisconsin Endowment.

Supplementary Information The online version contains supplementary material available at https://doi.org/10.1007/s11606-02006583-7.

\section{REFERENCES}

1. Hood CM, Gennuso KP, Swain GR, Catlin BB. County Health Rankings: Relationships Between Determinant Factors and Health Outcomes. Am J Prev Med. 2016;50(2):129-135. doi:https://doi.org/10.1016/j.amepre. 2015.08.024

2. Hawkins JM, Mitchell J. The Doctor Never Listens: Older African American Men's Perceptions of Patient-Provider Communication. Soc Work Res. 2018;42(1):57-63. doi:https://doi.org/10.1093/swr/svx028

3. Mitchell J, Williams E-DG, Perry R, Lobo K. "You Have to Be Part of the Process": A Qualitative Analysis of Older African American Men's Primary
Care Communication and Participation. Am J Mens Health. 2019;13(4):1557988319861569. doi:https://doi.org/10.1177/ 1557988319861569

4. Street RL Jr, Makoul G, Arora NK, Epstein RM. How does communication heal? Pathways linking clinician-patient communication to health outcomes. Patient Educ Couns. 2009;74(3):295-301. doi:https://doi.org/ 10.1016/j.pec.2008.11.015

5. Col NF, Solomon AJ, Springmann V, et al. Whose Preferences Matter? A Patient-Centered Approach for Eliciting Treatment Goals. Med Decis Making. 2018;38(1):44-55. doi:https://doi.org/10.1177/ 0272989X17724434

6. Bernabeo E, Holmboe ES. Patients, providers, and systems need to acquire a specific set of competencies to achieve truly patient-centered care. Health Aff . 2013;32(2):250-258. doi:https://doi.org/10.1377/ hlthaff.2012.1120

7. Britten N, Moore L, Lydahl D, Naldemirci O, Elam M, Wolf A. Elaboration of the Gothenburg model of person-centred care. Health Expect. 2017;20(3):407-418. doi:https://doi.org/10.1111/hex. 12468

8. Gobat N, Kinnersley P, Gregory JW, Robling $\mathbf{M}$. What is agenda setting in the clinical encounter? Consensus from literature review and expert consultation. Patient Educ Couns. 2015;98(7):822-829. doi:https://doi. org/10.1016/j.pec.2015.03.024

9. Cusatis R, Holt JM, Williams J, et al. The Impact of Patient-Generated Contextual Data on Communication in Clinical Practice: A Qualitative Assessment of Patient and Clinician Perspectives. Patient Educ Couns. Published online 2019. doi:https://doi.org/10.1016/j.pec.2019.10.020

10. Holt JM, Cusatis R, Asan O, et al. Incorporating patient-generated contextual data into care: Clinician perspectives using the Consolidated Framework for Implementation Science. Healthcare. Published online August 21, 2019:100369. doi:https://doi.org/10.1016/j.hjdsi.2019.100369

11. Cantor MN, Thorpe L. Integrating Data On Social Determinants Of Health Into Electronic Health Records. Health Aff 2018;37(4):585-590. doi:https://doi.org/10.1377/hlthaff.2017.1252

12. Dzau VJ, Balatbat CA. Health and societal implications of medical and technological advances. Sci Transl Med. 2018;10(463). doi:https://doi. org/10.1126/scitranslmed.aau4778

13. Dzau VJ, McClellan MB, McGinnis JM, et al. Vital Directions for Health and Health Care: Priorities From a National Academy of Medicine Initiative. JAMA. 2017;317(14):1461-1470. doi:https://doi.org/10. 1001/jama.2017.1964

14. Estiri H, Patel CJ, Murphy SN. Informatics can help providers incorporate context into care. Jamia Open. 2018;1(1):3-6. doi:https:// doi.org/10.1093/jamiaopen/ooy025

15. Furukawa MF, King J, Patel V, Hsiao C-J, Adler-Milstein J, Jha AK. Despite substantial progress In EHR adoption, health information exchange and patient engagement remain low in office settings. Health Aff . 2014;33(9):1672-1679. doi:https://doi.org/10.1377/hlthaff.2014.0445

16. Gold R, Cottrell E, Bunce A, et al. Developing Electronic Health Record (EHR) Strategies Related to Health Center Patients' Social Determinants of Health. J Am Board Fam Med. 2017;30(4):428-447. doi:https://doi. org/10.3122/jabfm.2017.04.170046

17. Hatef E, Weiner JP, Kharrazi $\mathbf{H}$. A public health perspective on using electronic health records to address social determinants of health: The potential for a national system of local community health records in the United States. Int J Med Inform. 2019;124:86-89. doi:https://doi.org/10. 1016/j.ijmedinf.2019.01.012

18. Binns-Calvey AE, Malhiot A, Kostovich CT, et al. Validating Domains of Patient Contextual Factors Essential to Preventing Contextual Errors: A Qualitative Study Conducted at Chicago Area Veterans Health Administration Sites. Acad Med. 2017;92(9):1287-1293. doi:https://doi. org/10.1097/ACM.0000000000001659

19. Keselman A, Logan R, Smith CA, Leroy G, Zeng-Treitler Q. Developing Informatics Tools and Strategies for Consumer-centered Health Communication. J Am Med Inform Assoc. 2008;15(4):473-483. doi:https://doi. org/10.1197/jamia.M2744

20. Hibbard JH, Stockard J, Mahoney ER, Tusler M. Development of the Patient Activation Measure (PAM): conceptualizing and measuring activation in patients and consumers. Health Serv Res. 2004;39(4 Pt 1):1005-1026. doi:https://doi.org/10.1111/j.1475-6773.2004.00269.x

21. Veinot TC, Mitchell H, Ancker JS. Good intentions are not enough: how informatics interventions can worsen inequality. J Am Med Inform Assoc. 2018;25(8): 1080-1088. doi:https://doi.org/10.1093/jamia/ocy052

22. Anderson M, Perrin A, Jiang J, Kumar M. $10 \%$ of Americans don't use the internet. Who are they? Pew Research Center. Published 2019. Accessed October 20, 2020. https://www.pewresearch.org/fact-tank/ 2019/04/22/some-americans-dont-use-the-internet-who-are-they/ 
23. Campos-Castillo C, Anthony D. Racial and Ethnic Differences in SelfReported Telehealth Use during the COVID-19 Pandemic: A Secondary Analysis of a U.S. Survey of Internet Users from Late March. J Am Med Inform Assoc. Published online September 7, 2020. doi:https://doi.org/ 10.1093/jamia/ocaa221

24. Anthony DL, Campos-Castillo C, Lim PS. Who Isn't Using Patient Portals And Why? Evidence And Implications From A National Sample Of US Adults. Health Aff. 2018;37(12):1948-1954. doi:https://doi.org/10. 1377/hlthaff.2018.05117

25. Din HN, McDaniels-Davidson C, Nodora J, Madanat H. Profiles of a Health Information-Seeking Population and the Current Digital Divide: CrossSectional Analysis of the 2015-2016 California Health Interview Survey. $J$ Med Internet Res. 2019;21(5):e11931. doi:https://doi.org/10.2196/11931

26. Goel MS, Brown TL, Williams A, Hasnain-Wynia R, Thompson JA, Baker DW. Disparities in enrollment and use of an electronic patient portal. J Gen Intern Med. 2011;26(10):1112-1116. doi:https://doi.org/ 10.1007/s11606-011-1728-3

27. Smith SG, O'Conor R, Aitken W, Curtis LM, Wolf MS, Goel MS. Disparities in registration and use of an online patient portal among older adults: findings from the LitCog cohort. $J$ Am Med Inform Assoc. 2015;22(4):888-895. doi:https://doi.org/10.1093/jamia/ocv025

28. Yamin CK, Emani S, Williams DH, et al. The digital divide in adoption and use of a personal health record. Arch Intern Med. 2011;171(6):568574. doi:https://doi.org/10.1001/archinternmed.2011.34

29. Kontos E, Blake KD, Chou WY, Prestin A. Predictors of eHealth usage: insights on the digital divide from the Health Information National Trends Survey 2012. J Med Internet Res. 2014;16(7):e172. doi:https://doi.org/ 10.2196/jmir.3117

30. Pérez-Stable EJ, Jean-Francois B, Aklin CF. Leveraging Advances in Technology to Promote Health Equity. Med Care. 2019;57 Suppl 6 Suppl 2:S101-S103. doi:https://doi.org/10.1097/MLR.0000000000001112

31. Holt JM, Cusatis R, Winn A, et al. The Impact of Previsit Contextual Data Collection on Patient-Provider Communication and Patient Activation: Study Protocol for a Randomized Controlled Trial. JMIR Res Protoc. 2020;9(9):e20309. doi:https://doi.org/10.2196/20309

32. Makoul G. Essential elements of communication in medical encounters: the Kalamazoo consensus statement. Acad Med. 2001;76(4):390-393. doi:https://doi.org/10.1097/00001888-200104000-00021

33. Sherman DK, Cohen GL. The Psychology of Self-defense: SelfAffirmation Theory. In: Advances in Experimental Social Psychology. Vol 38. Academic Press; 2006:183-242. doi:https://doi.org/10.1016/ S0065-2601(06)38004-5

34. Sherman DK, Hartson KA. Reconciling self-protection with self-improvement: Self-affirmation theory. In: Alicke MD, ed. Handbook of SelfEnhancement and Self-Protection (Vol 524). The Guilford Press, 2011:128 151. https://psycnet.apa.org/fulltext/2011-04015-006.pdf. Accessed 21 Sept 2019.

35. Makoul G, Krupat E, Chang C-H. Measuring patient views of physician communication skills: development and testing of the Communication Assessment Tool. Patient Educ Couns. 2007;67(3):333-342. doi:https:// doi.org/10.1016/j.pec.2007.05.005

36. Hibbard JH, Mahoney ER, Stockard J, Tusler M. Development and testing of a short form of the patient activation measure. Health Serv Res. 2005;40(6 Pt 1):1918-1930. doi:https://doi.org/10.1111/j.1475-6773. 2005.00438.x

37. Fowles JB, Terry P, Xi M, Hibbard J, Bloom CT, Harvey L. Measuring self-management of patients' and employees' health: further validation of the Patient Activation Measure (PAM) based on its relation to employee characteristics. Patient Educ Couns. 2009;77(1):116-122. doi:https:// doi.org/10.1016/j.pec.2009.02.018

38. Harris PA, Taylor R, Thielke R, Payne J, Gonzalez N, Conde JG Research electronic data capture (REDCap)-a metadata-driven methodology and workflow process for providing translational research informatics support. J Biomed Inform. 2009;42(2):377-381. doi:https://doi.org/ 10.1016/j.jbi.2008.08.010

39. Greenberg-Worisek AJ, Kurani S, Finney Rutten LJ, Blake KD, Moser RP, Hesse BW. Tracking Healthy People 2020 Internet, Broadband, and Mobile Device Access Goals: An Update Using Data From the Health Information National Trends Survey. J Med Internet Res. 2019;21(6):e13300. doi:https://doi.org/10.2196/13300

40. Dyer N, Sorra JS, Smith SA, Cleary PD, Hays RD. Psychometric properties of the Consumer Assessment of Healthcare Providers and
Systems (CAHPS $®$ ) Clinician and Group Adult Visit Survey. Med Care 2012;50 Suppl:S28-S34. doi:https://doi.org/10.1097/MLR. Ob013e31826cbcOd

41. Hays RD, Bjorner JB, Revicki DA, Spritzer KL, Cella D. Development of physical and mental health summary scores from the patient-reported outcomes measurement information system (PROMIS) global items. Qual Life Res. 2009;18(7):873-880. doi:https://doi.org/10.1007/s11136-009-9496-9

42. Chew LD, Griffin JM, Partin MR, et al. Validation of screening questions for limited health literacy in a large VA outpatient population. J Gen Intern Med. 2008;23(5):561-566. doi:https://doi.org/10.1007/s11606-0080520-5

43. Hernán MA, Hernández-Diaz S. Beyond the intention-to-treat in comparative effectiveness research. Clin Trials. 2012;9(1):48-55. doi:https://doi.org/10.1177/1740774511420743

44. Hernán MA, Robins JM. Per-Protocol Analyses of Pragmatic Trials. $N$ Engl J Med. 2017;377(14):1391-1398. doi:https://doi.org/10.1056/ NEJMsm 1605385

45. Finkelstein A, Taubman S, Wright B, et al. The Oregon Health Insurance Experiment: Evidence from the First Year. Published online July 2011. doi:https://doi.org/10.3386/w17190

46. Imbens GW, Angrist JD. Identification and Estimation of Local Average Treatment Effects. Econometrica. 1994;62(2):467-475. doi:https://doi. org/10.2307/2951620

47. Jakobsen JC, Gluud C, Wetterslev J, Winkel P. When and how should multiple imputation be used for handling missing data in randomised clinical trials - a practical guide with flowcharts. BMC Med Res Methodol. 2017;17(1):162. doi:https://doi.org/10.1186/s12874-017-0442-1

48. Finkelstein A, Zhou A, Taubman S, Doyle J. Health Care Hotspotting A Randomized, Controlled Trial. N Engl J Med. 2020;382(2):152-162. doi:https://doi.org/10.1056/NEJMsa1906848

49. Singh Ospina N, Phillips KA, Rodriguez-Gutierrez R, et al. Eliciting the Patient's Agenda- Secondary Analysis of Recorded Clinical Encounters. J Gen Intern Med. 2019;34(1):36-40. doi:https://doi.org/10.1007/s11606018-4540-5

50. Saba GW, Wong ST, Schillinger D, et al. Shared decision making and the experience of partnership in primary care. Ann Fam Med. 2006;4(1):54-62. doi:https://doi.org/10.1370/afm.393

51. Epstein RM, Street RL Jr. The values and value of patient-centered care. Ann Fam Med. 2011;9(2):100-103. doi:https://doi.org/10.1370/afm. 1239

52. Davis K, Schoenbaum SC, Audet A-M. A 2020 vision of patient-centered primary care. J Gen Intern Med. 2005;20(10):953-957. doi:https://doi. org/10.1111/j.1525-1497.2005.0178.x

53. Williams DR, Lawrence JA, Davis BA. Racism and Health: Evidence and Needed Research. Annu Rev Public Health. 2019;40:105-125. doi:https://doi.org/10.1146/annurev-publhealth-040218-043750

54. Wosik J, Fudim M, Cameron B, et al. Telehealth transformation: COVID-19 and the rise of virtual care. J Am Med Inform Assoc. 2020;27(6):957-962. doi:https://doi.org/10.1093/jamia/ocaa067

55. Kriegel Gila, Bell Sigall, Delbanco Tom, Walker Jan. Covid-19 as Innovation Accelerator: Cogenerating Telemedicine Visit Notes with Patients. Catalyst non-issue content. 1(3). doi:https://doi.org/10.1056/ CAT.20.0154

56. Nathan AG, Marshall IM, Cooper JM, Huang ES. Use of Decision Aids with Minority Patients: a Systematic Review. J Gen Intern Med 2016;31(6):663-676. doi:https://doi.org/10.1007/s11606-016-3609-2

57. Wisconsin Department of Health Services. Annual Wisconsin Birth and Infant Death Report.; 2019. Accessed July 7, 2020. https://www.dhs. wisconsin.gov/stats/births/index.htm

58. Otado J, Kwagyan J, Edwards D, Ukaegbu A, Rockcliffe F, Osafo N. Culturally Competent Strategies for Recruitment and Retention of African American Populations into Clinical Trials. Clin Transl Sci. 2015;8(5):460466. doi:https://doi.org/10.1111/cts. 12285

59. Krieger N, Williams DR, Moss NE. Measuring social class in US public health research: concepts, methodologies, and guidelines. Annu Rev Public Health. 1997;18:341-378. doi:https://doi.org/10.1146/annurev. publhealth. 18.1.341

60. Hays RD, Schalet BD, Spritzer KL, Cella D. Two-item PROMIS $₫$ global physical and mental health scales. J Patient Rep Outcomes. 2017;1(1):2. doi:https://doi.org/10.1186/s41687-017-0003-8

Publisher's Note: Springer Nature remains neutral with regard to jurisdictional claims in published maps and institutional affiliations. 